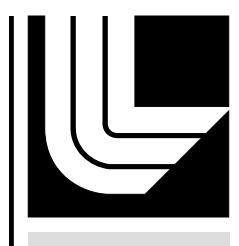

LAWRENCE LIVERM ORE N A TIO NAL LABORATORY

\title{
Evaluating GC/MS Performance
}

Armando Alcaraz, Arden Dougan

November 29, 2006 
This document was prepared as an account of work sponsored by an agency of the United States government. Neither the United States government nor Lawrence Livermore National Security, LLC, nor any of their employees makes any warranty, expressed or implied, or assumes any legal liability or responsibility for the accuracy, completeness, or usefulness of any information, apparatus, product, or process disclosed, or represents that its use would not infringe privately owned rights. Reference herein to any specific commercial product, process, or service by trade name, trademark, manufacturer, or otherwise does not necessarily constitute or imply its endorsement, recommendation, or favoring by the United States government or Lawrence Livermore National Security, LLC. The views and opinions of authors expressed herein do not necessarily state or reflect those of the United States government or Lawrence Livermore National Security, LLC, and shall not be used for advertising or product endorsement purposes.

This work performed under the auspices of the U.S. Department of Energy by Lawrence Livermore National Laboratory under Contract DE-AC52-07NA27344. 


\section{Evaluating GC/MS Performance}

1) Evaluating the chemical background in the GC/MS system (system background) and solvent purity.

- This procedure will allow the analyst to verify that the GC/MS is free of chemical interferences or contamination and verify the solvent being utilized is free of interferences

- Conduct a GC/MS analysis without injecting a solvent (system background)

$\circ$ Conduct a $\mathrm{GC} / \mathrm{MS}$ analysis inject $1 \mathrm{uL}$ of $\mathrm{CH}_{2} \mathrm{Cl}_{2}$ solvent (Solvent background)

GC conditions:

Injector Temperature $\left({ }^{\circ} \mathrm{C}\right)$ : Injector Temperature is typically set at $250^{\circ}$

Transferline Temperature $\left({ }^{\circ} \mathrm{C}\right)$ : The Transferline Temperature is typically set at $280^{\circ} \mathrm{C}$

Constant flow $(\mathrm{Sec} . / \mathrm{cm} 2)$ : This value, in seconds per cubic cm. Typically, set at 32.

Splitless mode (Sec.): This value, in seconds, is the time before the purge valve opens. Typically, set at 45 seconds.

Starting Temperature $\left({ }^{\circ} \mathrm{C}\right)$ : The Starting Temperature value can be set at $40^{\circ} \mathrm{C}$.

Hold Time 1 (Min.): Hold Time 1 is the amount of time, in minutes at the

Starting Temperature that Ramp 1 Temperature is held. Typically set at 3

minutes.

Ramp 1 Rate $\left({ }^{\circ} \mathrm{C} / \mathrm{Min}.\right)$ : Ramp 1 Rate is the temperature rise per unit time and has a typically value of $8^{\circ} \mathrm{C}$ per minute to $300^{\circ} \mathrm{C}$.

Hold Time 2 (Min.): Hold Time 2 is the amount of time, in minutes at the final Temperature that Ramp 1 Temperature is held. Temperature is held at $300^{\circ} \mathrm{C}$ for 3 minutes.

MS conditions:

Electronic : 40 to $500 \mathrm{amu}$

Scan Range: $30-600 \mathrm{~m} / \mathrm{z}$

Scan time: 0.7 sec.

Mass Resolution: $07 \mathrm{u}$

Electron energy 1: $70 \mathrm{eV}$

The total ion chromatograms (TIC) from a bakeout and solvent should be void of any large chromatographic peaks (see figure 1).

2) Autotune using the PFTBA calibrant

- First selecting the autotune option and click on standard autotune. The software program will generate final tune report similar to figure 2. If there are any MS tuning problems (e.g., dirty source, air leak, etc..) the tuning process will fail. 
- Be sure to save the tune file before proceeding to the next step.

3) Run an "Air and Water Check"

- By selecting View - Diagnostics/Vacuum Control - Vacuum - Air and Water Check. A Yes/No dialogue box will appear; select No (use current values). It is very important to select No! Otherwise the tune values are drastically altered.

- The software program will generate a water/air report similar to figure 3.

4) Evaluating the GC/MS system with a performance standard.

- This procedure should allow the analyst to verify that the chromatographic column and associated components are working adequately to separate the various classes of chemical compounds (e.g., hydrocarbons, alcohols, fatty acids, aromatics, etc..).

- Use the same GC/MS conditions used to collect the system background and solvent check (part 1 of this document)

- Figure 5 is an example of a commercial GC/MS column test mixture used to evaluate $\mathrm{GC} / \mathrm{MS}$ prior to analysis. 


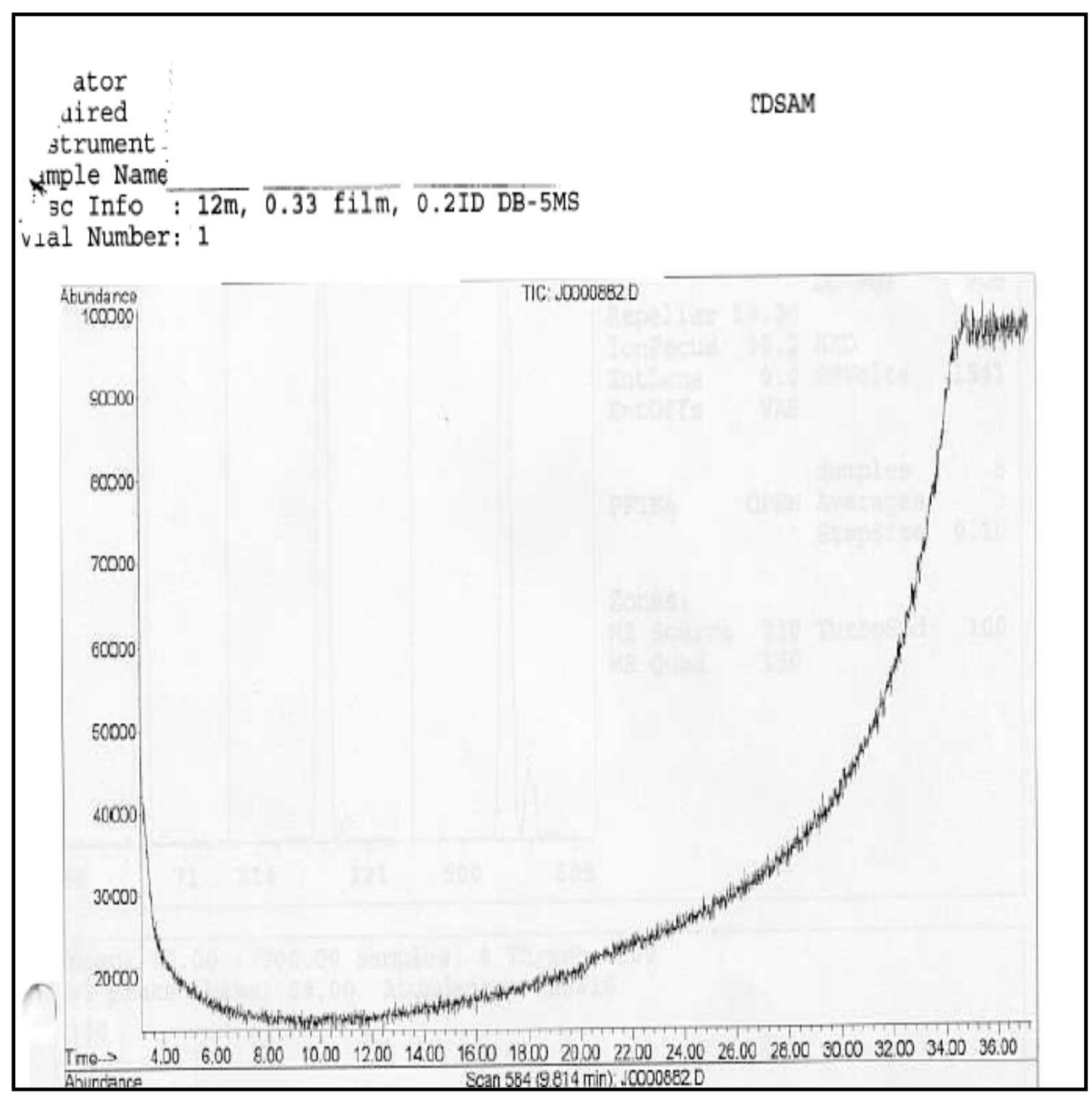

Figure 1. GC/MS total ion chromatogram (TIC) of a system blank 


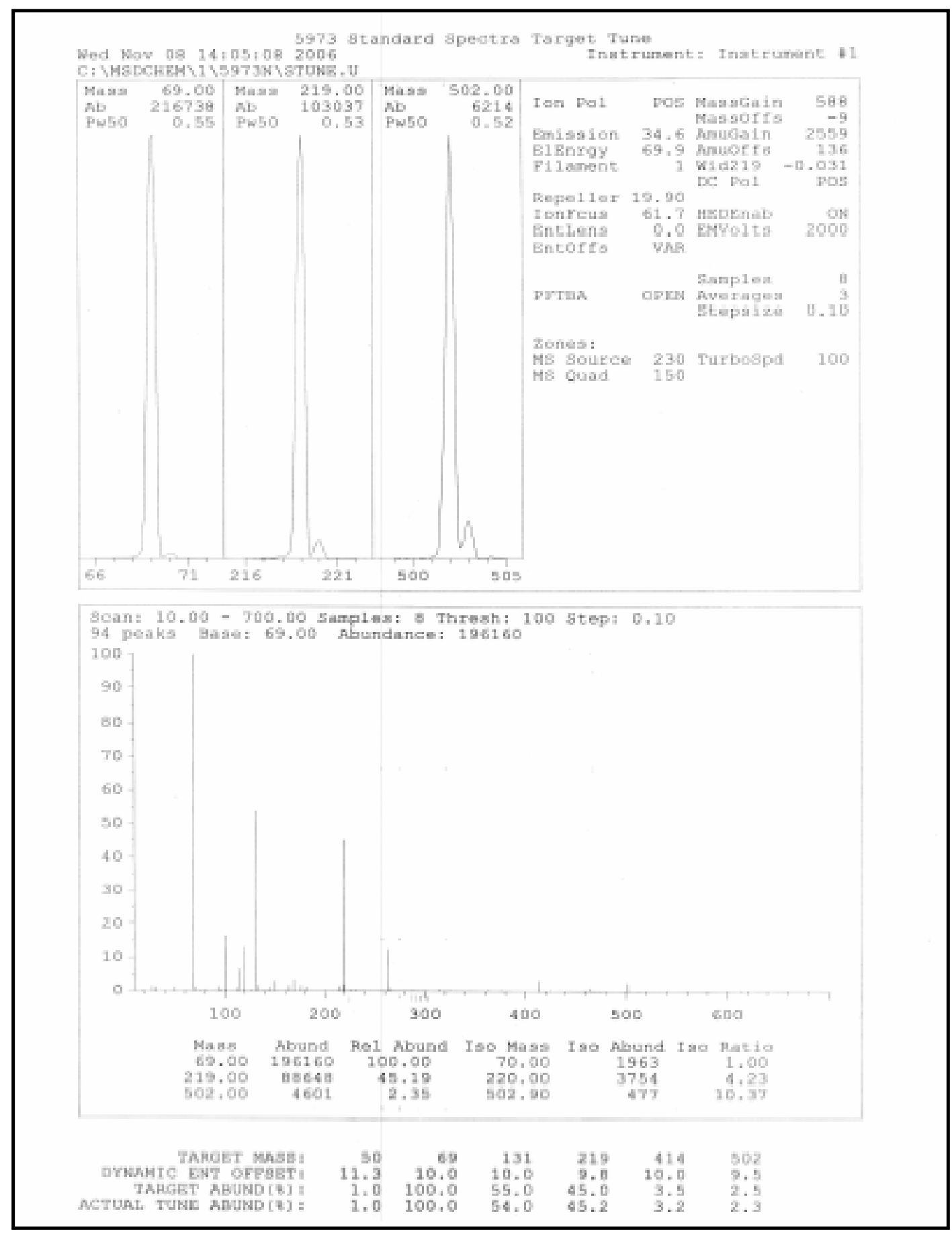

Figure 2. Example of an acceptable tune report 


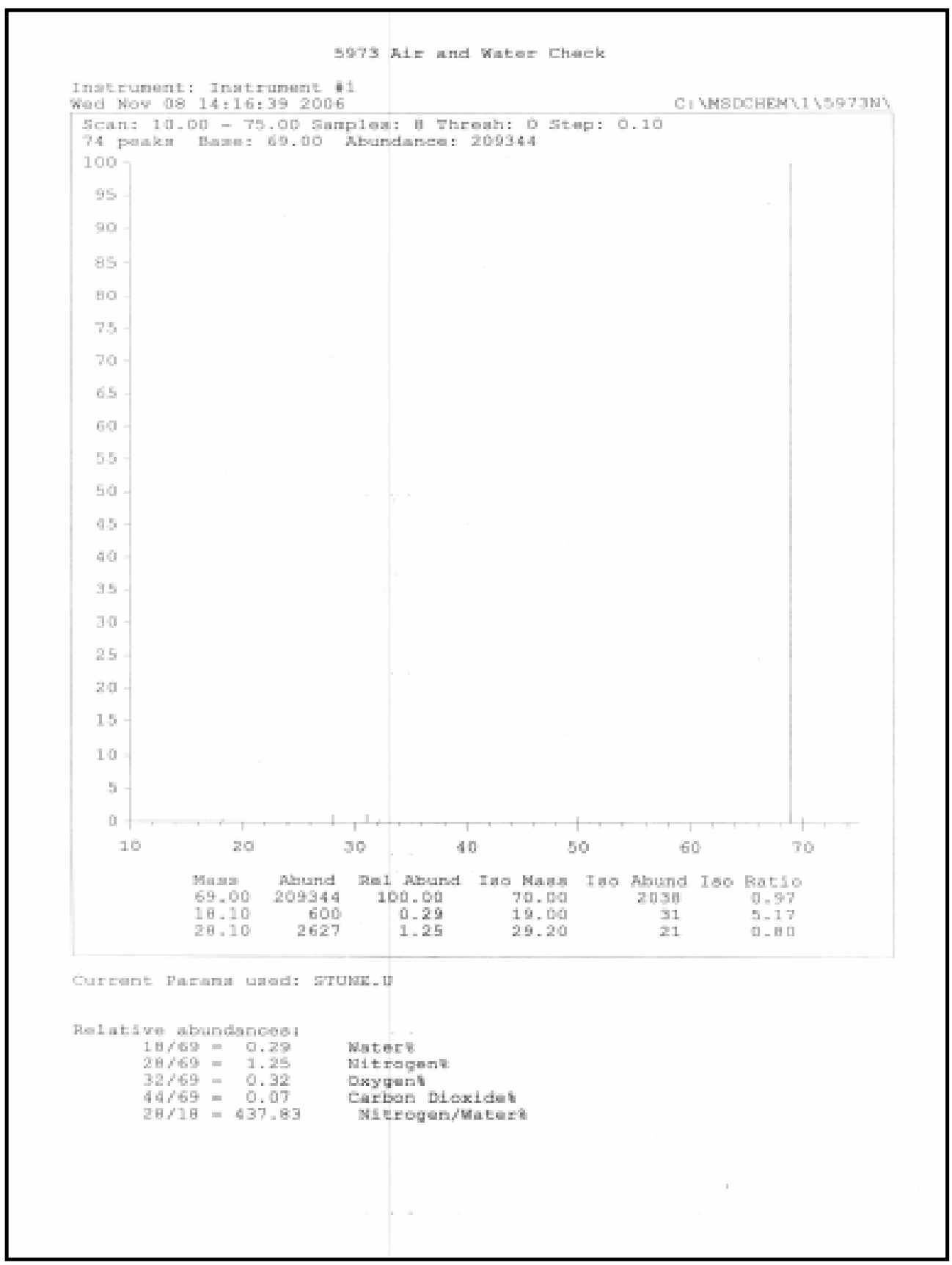

Figure 3. Example of an acceptable air and water check report 


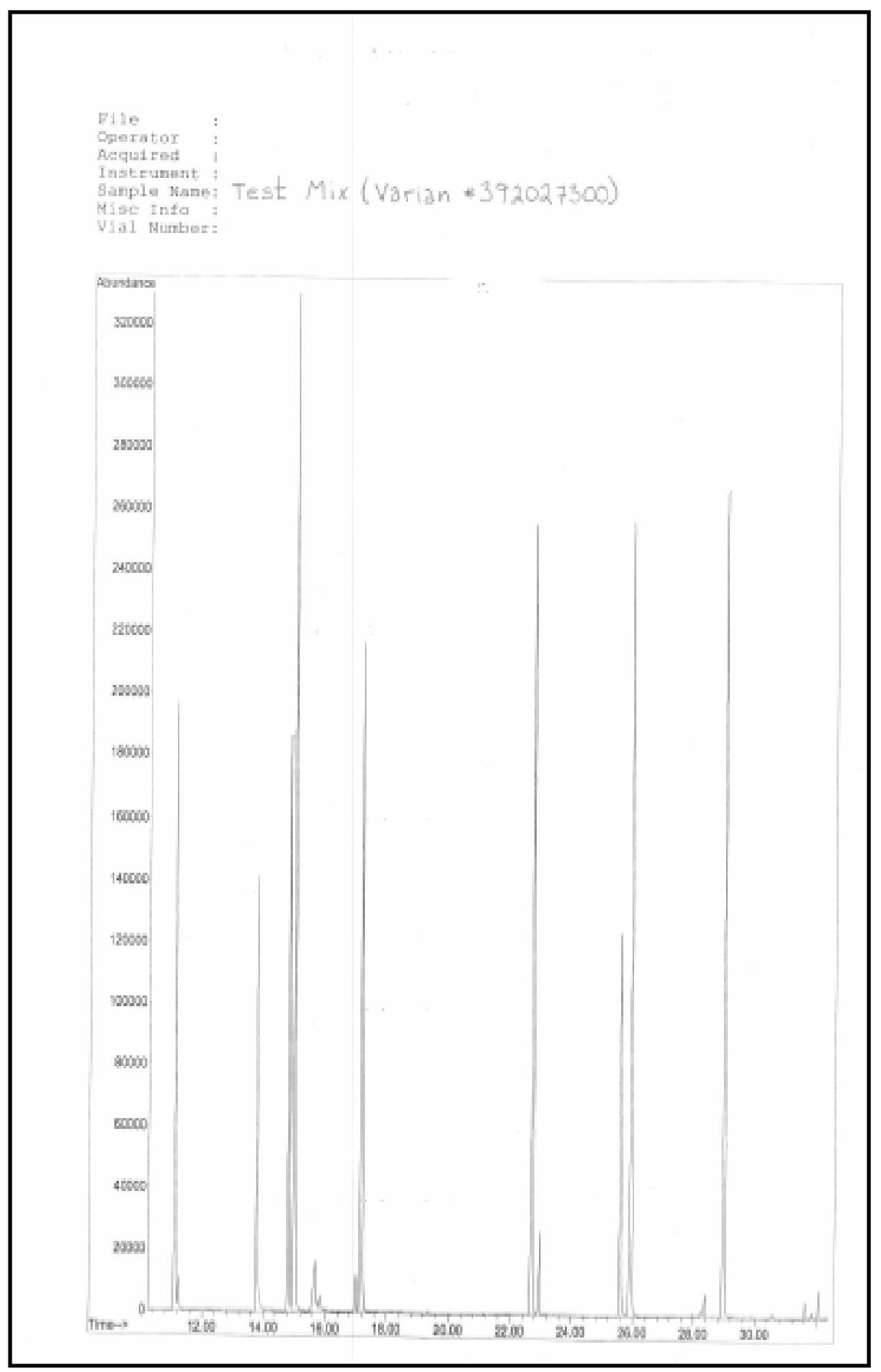

Figure 4. Example of an total ion chromatogram (TIC) of a performance standard 




Figure 5. Example of a commercial GC/MS column test mixture. 